\title{
Effects of granulocyte-colony-stimulating factor on progenitor cell mobilization and heart perfusion and function in normal mice
}

\author{
MARIE DELGAUDINE ${ }^{1}$, BERNARD LAMBERMONT $^{2}$, PATRIZIO LANCELLOTTI ${ }^{3}$, \\ VÉRONIQUE ROELANTS ${ }^{4,5}$, STÉPHAN WALRAND ${ }^{5}$, JEAN-LOUIS VANOVERSCHELDE ${ }^{4}$, \\ LUC PIERARD $^{3}$, ANDRÉ GOTHOT ${ }^{1} \&$ YVES BEGUIN $^{1}$ \\ ${ }^{1}$ Giga-Research, Hematology Unit, University of Liège, Liège, Belgium, ${ }^{2}$ Department of Medicine, Medical Intensive Care \\ Unit, University of Liège, Liège, Belgium, ${ }^{3}$ Department of Medicine, Division of Cardiology, University of Liège, Liège \\ Belgium, ${ }^{4}$ Catholic University of Leuven, Division of Cardiology, Brussels, Belgium, and ${ }^{5}$ Catholic University of Leuven, \\ IMRE Unit, Brussels, Belgium
}

Marie Delgaudine, conception and design, collection and/or assembly of data, data analysis and interpretation, manuscript writing, final approval of manuscript; Bernard Lambermont, Patrizio Lancellotti, Véronique Roelants and Stéphan Walrand, collection and/or assembly of data, data analysis and interpretation, final approval of manuscript; Fean-Louis Vanoverschelde and Luc Pierard, data analysis and interpretation, final approval of manuscript; André Gothot, conception and design, data analysis and interpretation, final approval of manuscript; Yves Beguin, conception and design, data analysis and interpretation, manuscript writing, final approval of manuscript

\begin{abstract}
Background aims. Mobilization of stem cells and progenitor cells from the bone marrow (BM) into the peripheral blood (PB) by granulocyte-colony-stimulating factor (G-CSF) is being investigated for cardiac regeneration in ischemic heart disease. However, hematopoietic (HPC), mesenchymal (MPC) and endothelial (EPC) progenitor mobilization have not been optimized and the effect of G-CSF on myocardial perfusion and cardiac function in a normal heart has never been studied. Methods. Normal mice were injected daily for 1-10 days with subcutaneous recombinant human G-CSF. PB and BM were evaluated for HPC and EPC by flow cytometry and HPC and MPC by hematopoietic (CFU-GM) and mesenchymal (CFU-F) colony assays. Echocardiography, microSPECT imaging, cardiac catheterization and immunohistochemistry were performed in mice treated for 10 days. Results. HPC and CFU-GM in PB peaked after 2 days, CFU-F after 4 days and EPC after 3 days. Thereafter, while HPC temporally decreased before showing a second peak, EPC remained detectable only at low levels. In BM, hematopoietic stem cells (HSC) and CFU-GM did not increase much overall but peaked twice on days 2 and 7. EPC (peak on day 7) production increased in the BM, but CFU-F formation declined considerably after day 2. G-CSF enhanced myocardial perfusion and vascularization but impaired hemodynamic performance of the heart through apparently increased ventricular wall rigidity. Conclusions. G-CSF induces the mobilization of HPC, EPC and CFU-F progenitors in PB according to very different patterns, and has a significant impact on perfusion and function of the normal heart.
\end{abstract}

Key Words: granulocyte-colony-stimulating factor, mobilization, normal heart, progenitor cells, stem cells

\section{Introduction}

Experiments in animal models (1-3) and clinical trials $(4,5)$ have investigated the potential of stem cells to repair a diseased myocardium. Cells have been obtained mostly from either bone marrow (BM) or peripheral blood $(\mathrm{PB})$ after mobilization by various pharmacologic agents. Among these, granulocyte-colony-stimulating factor (G-CSF) has been used most frequently.

Hematopoietic and non-hematopoietic stem and progenitor cells reside mainly in the BM, but a few circulate in the $\mathrm{PB}$ under physiologic conditions and in higher concentrations after pharmacologic 
mobilization. Mobilization of hematopoietic stem cells (HSC) and progenitor cells (HPC) into PB can be induced by the administration of G-CSF, granulocyte-macrophage colony-stimulating factor (GM-CSF), interleukin (IL)-3, IL-8, stem cell factor (SCF), the CXCR2 agonist GRO $\beta$ and the CXCR4 antagonist AMD3100, or combination of these (6). G-CSF induces mobilization in a time- and dose-dependent manner, eliciting a gradual increase of HPC in PB, peaking after 4-7 days in humans. G-CSF-induced peripheral blood stem cells (PBSC) have replaced BM as the major source of HSC for transplantation, providing faster engraftment with equivalent long-term outcomes (7). HSC mobilization is a multistep process involving cytokine-induced functional changes in the adhesion molecule profile of stem cells (SC) and disruption of their adhesive interactions with $\mathrm{BM}$ stromal cells, followed by their release, migration and homing (8). The role of adhesion molecules, such very late antigen-4 (VLA-4) and $\mathrm{P} / \mathrm{E}$ selectins, the central function of stromalderived factor-1 (SDF-1) and CXCR4 interactions, and the involvement of proteolytic enzymes such as elastase, cathepsin $\mathrm{G}$ and various metaloproteinases, have been well established $(9,10)$.

The $\mathrm{BM}$ is also a reservoir for mesenchymal stromal cells (MSC) and endothelial progenitors (EPC) (11-13). The demonstration of MSC in PB under physiologic conditions or following G-CSF administration remains controversial, but there is growing evidence that these cells can enter the peripheral circulation (14-16). The mechanisms and kinetics of MSC and EPC mobilization from the BM into the $\mathrm{PB}$ are not well characterized. In particular, the patterns of HSC, MSC and EPC mobilization have not been compared and the relationship between their kinetics in $\mathrm{PB}$ and $\mathrm{BM}$ has not been examined.

The effects of G-CSF administration on myocardial perfusion and hemodynamic performance in the normal heart have also never been studied. Whereas the effects of G-CSF in ischemic heart disease has been examined in numerous studies $(17,18)$, nothing is known about the potential effects of G-CSF itself on the heart. Therefore, the second aim of our study was to investigate the effects of G-CSF on heart structure and function, using an array of sophisticated techniques including immunohistochemistry, echocardiography, pressure-volume (PV) measurements and perfusion imaging.

\section{Methods}

\section{Animal experiments}

The investigation conformed with the Guide for the Care and Use of Laboratory Animals published by the National Institutes of Health (NIH, Bethesda, MD,
USA; publication number 85-23, revised 1996) and was approved by the animal care ethical committee of the University of Liège (Liège, Belgium). Female C57B1/6 mice 2 months of age were injected daily with recombinant human G-CSF $\left(\right.$ Neupogen ${ }^{\circledR}$ ), $50 \mu \mathrm{g} / \mathrm{kg}$ subcutaneously, for 1-10 days. Twelve animals were killed each day and their heart, blood (collected from the inferior vena cava) and BM (from both femurs and tibias) collected. Two other groups of 12 animals each were injected with either saline or G-CSF daily for 10 days, and echocardiography and microSPECT perfusion imaging were performed on day 11 and cardiac catheterization and immunohistochemistry on day 12 .

\section{Blood parameters and flow cytometry analysis}

White blood cells (WBC) and BM cells were counted in an ABX Micros 60 automatic cell counter (HORIBA ABX Diagnostics, Antwerp, Belgium). Blood and $B M$ cells were washed and the supernatant was eliminated. Five microliters of monoclonal antibody (MAb) anti-CD45, CD34, CD31 or Sca1 (all IgG2b from BD Biosciences, Erembodegem, Belgium) were added to the pellet and the cells were incubated for $30 \mathrm{~min}$ at $4^{\circ} \mathrm{C}$. Cells were then washed and $5 \mu \mathrm{L}$ allophycocyanin (APC)-conjugated goat anti-rat immunoglobulin (Ig) added. After incubation for 30 min at $4^{\circ} \mathrm{C}$, red cells were lyzed with $\mathrm{NH}_{4} \mathrm{Cl}$ for 10 min and nucleated cells were washed and fixed in phosphate-buffered saline (PBS) $1 \%$ formaldehyde. Samples were analyzed on a FACSCANTO (BD Biosciences). A minimum of 400000 cells was acquired by sample. HPC and EPC were evaluated as cells with $\mathrm{CD} 45^{+} \mathrm{Kit}^{+} \mathrm{Sca}^{+}$and $\mathrm{CD} 45^{-} \mathrm{CD} 34^{+} \mathrm{CD} 31^{+}$ phenotypes, respectively. Absolute cell counts were calculated from the total WBC count and percentage positive cells.

\section{Granulocyte-macrophage colony-forming units}

Cells were plated at $5 \times 10^{4}$ cells/35-mm dish for BM and $2 \times 10^{5}$ cells $/ 35-\mathrm{mm}$ dish for blood in Methocult ${ }^{\circledR}$ GF M3434 media (Stemcell Technologies, Vancouver, Canada) for 16 days. After 2 weeks, numbers of granulocyte-macrophage colony-forming units (CFU-GM) were scored with an inverted microscope at $\times 40$ magnification.

\section{Fibroblast colony-forming units}

Cells were plated at $5 \times 10^{4}$ cells $/ 25-\mathrm{cm}^{2}$ flask for $\mathrm{BM}$ and $2 \times 10^{5}$ cells $/ 25-\mathrm{cm}^{2}$ flask for blood in Dulbecco's modified Eagle medium (DMEM) with $10 \%$ fetal bovine serum (FBS; Gibco, Merelbeke, Belgium), $100 \mathrm{U} / \mathrm{mL}$ penicillin and $100 \mu \mathrm{g} / \mathrm{mL}$ streptomycin. The medium was changed every 3 days for 
a total of 21 days. Plates were then fixed in methanol and stained with hematoxylin-eosin at room temperature (RT) for $10 \mathrm{~min}$. All visible colonies were counted.

\section{Immunohistochemical analyzes}

Hearts were collected and embedded in TissueTek OCT (Sakura, Zoeterwoude, the Netherlands). The samples were cut to yield $10-\mu \mathrm{m}$ thick cryostat sections, and fixed in $10 \%$ methanol for $10 \mathrm{~min}$ at $-20^{\circ} \mathrm{C}$. Endothelial cells were studied with a rat anti-mouse CD31 (PECAM-1) MAb (BD Biosciences) for $60 \mathrm{~min}$ at RT and revealed by incubation with a biotin-conjugated rabbit anti-rat MAb (Dako, Heverlee, Belgium) at 1:400 for $30 \mathrm{~min}$ at RT followed by a streptavidin/HRP-conjugated antibody (Dako) at 1:500 for $30 \mathrm{~min}$ at RT. Imaging was performed with a confocal microscope. The number of $\mathrm{CD} 31^{+}$ arterioles was counted in eight slides per heart. Nuclei were counterstained with hematoxylin-eosin.

\section{Immunofluorescence analysis}

Fibroblast colony-forming units (CFU-F) were permeabilized with $0.01 \%$ Triton X-100 and studied with goat polyclonal IgG anti-CD73, anti-CD31 or anti-CD45 (Santa Cuz, Heidelberg, Germany) at 1:500 for $60 \mathrm{~min}$ at RT. CFU-F were washed and rhodamine-conjugated rabbit anti-goat polyclonal IgG (Abcam, Cambridge, UK) was added. Imaging was performed with a fluorescence microscope.

\section{Echocardiography}

Echocardiography was performed using a VIVID 7 echocardiograph and an i13L probe (General Electrics, Horten, Norway). Heated contact gel was applied to maintain a stable heart rate (HR). Conventional measurements [left ventricular (LV) diameters, anterior wall (AW) and posterior wall (PW) thickness and thickening] were obtained from grayscale $\mathrm{M}$-mode tracings at the level of the papillary muscles. LV end-systolic and end-diastolic volumes and LV ejection fraction (LVEF) were measured with the Teicholtz method. Tissue Doppler images were obtained from the parasternal short-axis view at the midventricular level, at a frame rate of $>300 \mathrm{frames} / \mathrm{s}$ and a depth of $1 \mathrm{~cm}$. Radial systolic strain was measured over an axial distance of $0.6 \mathrm{~mm}$. The temporal smoothing filters were turned off for all measurements. Peak systolic strain was averaged over three consecutive cardiac cycles.

\section{microSPECT imaging}

Animals were injected with $173 \pm 27 \mathrm{MBq}$ Tc-99m Sestamibi in the tail vein. To avoid gallbladder accumulation of Tc-99m Sestamibi cleared through the hepatobiliary system, $0.1 \mu \mathrm{g} / \mathrm{kg}$ cholecystokinin was injected intraperitoneally $2 \mathrm{~h}$ after Tc-99m Sestamibi. The animals were scanned $30 \mathrm{~min}$ later under anesthesia [ketamine $(50 \mathrm{mg} / \mathrm{kg})$ and xylazine $(2.5 \mathrm{mg} / \mathrm{kg}$ )] using a microSPECT (Linoview SPECT System, Amsterdam, the Netherlands) during $30 \mathrm{~min}$. The characteristics of the microSPECT system have been described elsewhere (19) and it was recently validated for myocardial infarct size measurement in mice by comparison with histology (20). Data were reconstructed using the expectation maximization maximum likelihood (EM-ML) algorithm without attenuation or resolution correction. The regions of interest (ROI) were drawn manually on each transverse slice of the left ventricle. The total number of counts in each ROI was corrected using the microSPECT system sensitivity. In each left ventricle, the percentage of injected activity was calculated at D0 and D10 and the results expressed as a ratio of mean LV uptake at D10 and D0 (D10/D0).

\section{Hemodynamic measurements}

PV loops were obtained under ketamine and xylasine anesthesia by descending a 1.4-F catheter with pressure and conductance sensors (Millar Instrument, Houston, TX, USA) through the right carotid artery into the left ventricle of mice placed on a heating table at $37^{\circ} \mathrm{C}$. Before implantation, calibration of the catheter was performed according to the manufacturer's recommendations. In brief, six cylindrical holes ranging from 13.2 to $172.3 \mu \mathrm{L}$ were filled with fresh heparinized mouse blood. From the measured raw conductance signals, the known cylinder volumes were plotted against the conductance and the regression equation calculated. To determine parallel conductance in animals, a small hypertonic saline bolus of $10 \mu \mathrm{L}$ was given intravenously. The induced change in conductivity of the blood allowed the separation of LV blood volume from parallel conductance as a result of the surrounding tissues. After instrumentation, data obtained from PV loops were analyzed with the PVAN 3.4 software (Millar Instrument). LV PV signals were acquired in steady state to quantify general hemodynamic conditions: $\mathrm{HR}$, stroke volume, cardiac output (CO), LV enddiastolic volume (EDV), LVEF, LV end-diastolic (EDP) and systolic (ESP) pressures were assessed. Stroke work was determined as the area of the PV loop. The time constant of isovolumic relaxation (Tau) was calculated as the slope of the relationship between a linear regression of $\mathrm{d} P / \mathrm{d} t_{\max }$ and pressure. To obtain the slope (Ees) of the end-systolic PV relationship, a load-independent index of systolic function, PV loops were also recorded during a gradual 
pre-load reduction obtained by gently compressing the inferior vena cava.

\section{Statistical analyzes}

Data are shown as mean \pm SD. The Gaussian distribution of the population was verified. Comparisons between groups were done using two-tailed Student's $t$-tests or by two-way ANOVA. The between-observers reproducibility was determined by Bland-Altman analysis. A P value $<0.05$ was considered statistically significant.

\section{Results}

Heart weight and immunohistochemistry

Heart weight or heart-to-body weight ratios were not influenced by G-CSF administration (Figure 1). The number of $\mathrm{CD} 31^{+}$arterioles was higher $(P<0.001)$ in mice treated with G-CSF $(2.48 \pm 0.68)$ compared with those receiving saline injections $(1.90 \pm 0.67)$ (Figure 2).

\section{Blood and BM parameters}

Hematocrits (Hct) increased on day 1 after starting G-CSF injections and stayed higher than in untreated mice throughout the study (Figure 3). WBC in BM decreased from day 1 to day 4 before bouncing back to intermediate values thereafter, while WBC in PB increased in the first 4 days before returning to baseline levels thereafter, thus mirroring the marrow pattern of evolution.

\section{FACS analysis and CFU assays of progenitor cells}

The number of HPC in BM peaked twice, at days 2 and 7, followed each time by a decline in BM accompanied by a major increase in PB (Figure 4). The number of CFU-GM in BM was also highest on days 2 and 7 , each time followed by a decline, and their mobilization in $\mathrm{PB}$ was evident after day 1, peaking on days 2-3. Marrow CFU-F decreased considerably after day 2 , whereas their numbers in PB increased markedly on day 2 and remained at a constant level for several days, before returning toward baseline values at the end of the experiment. We performed CD45-CD14 or CD45-CD31 double staining on CFU-F colonies. No doubly positive cells were detected. Flow cytometric analysis of cells within the CFU-F showed that these colonies did not contain cells positive for CD34 or CD45, and contained $2 \% \mathrm{CD} 11 \mathrm{~b}^{+}$cells, $60 \% \mathrm{CD} 106^{+}$and $89 \%$ $\mathrm{SCA}^{+}$cells. These colonies thus consisted mainly of mesenchymal progenitor cells (MPC). Marrow EPC increased steadily to day 7 , before returning
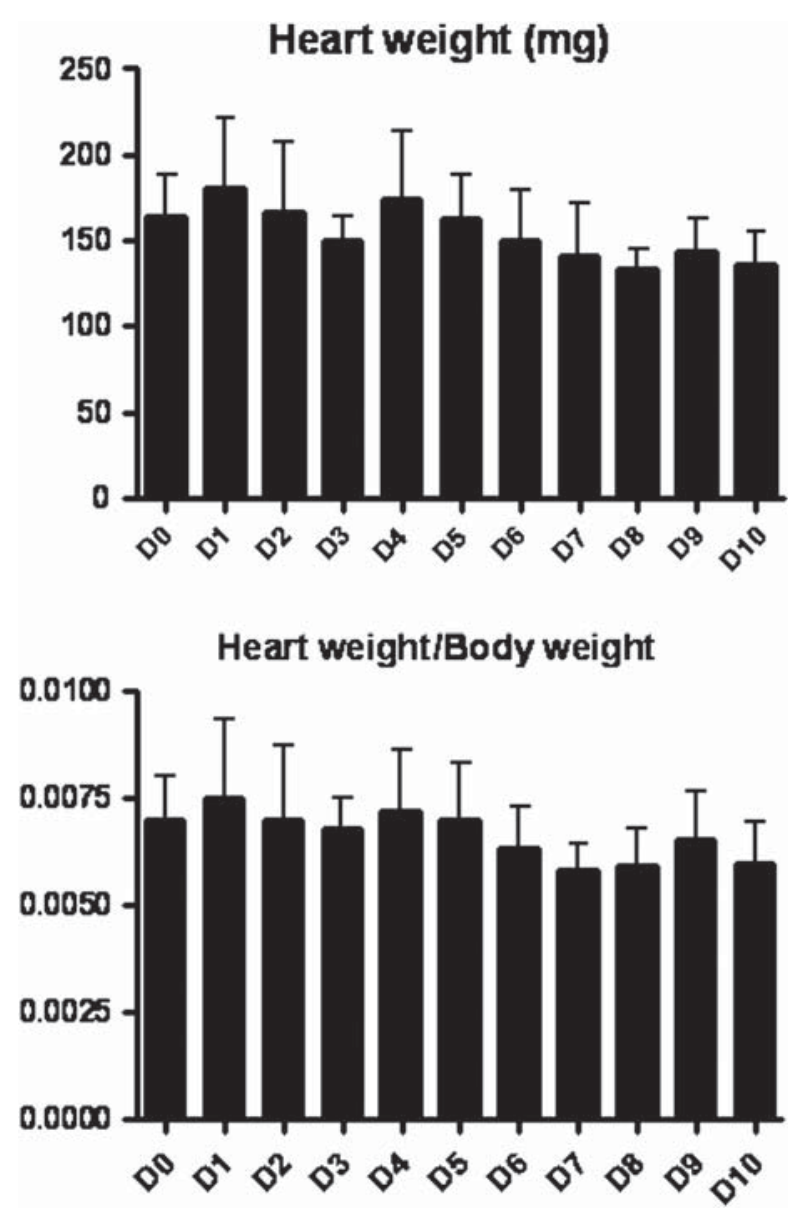

Figure 1. Heart weight (mg) and heart-to-body weight ratio (mg/mg) in mice before (day 0) and after 1-10 days of G-CSF therapy (NS).

to baseline thereafter. In the meantime, PB EPC jumped on day 3 but decreased to intermediate levels from day 5 onwards.

\section{microSPECT imaging}

The ratio of mean LV uptake between D10 and D0 (D10/D0) was $0.90 \pm 0.22$ in control mice and $1.30 \pm 0.41$ in G-CSF-treated mice $(P<0.05)$.

\section{Echocardiography}

LV dimensions and function were evaluated by echocardiography on day 11 , i.e. $24 \mathrm{~h}$ after the last dose of G-CSF or saline (Table I). HR was comparable in the two groups. LV posterior wall dimension (LVPW) $(P<001)$ and $\operatorname{LVEF}(P<0.05)$ were smaller in G-CSF-treated mice. Strains in the anterior $(P<0.01)$ and posterior $(P<0.05)$ walls were reduced after 10 days of G-CSF. The other parameters remained unchanged and HR was regular. The inter-observer reproducibility of strain parameters was excellent. There was a strong correlation between the two observers (strain in anterior wall, 

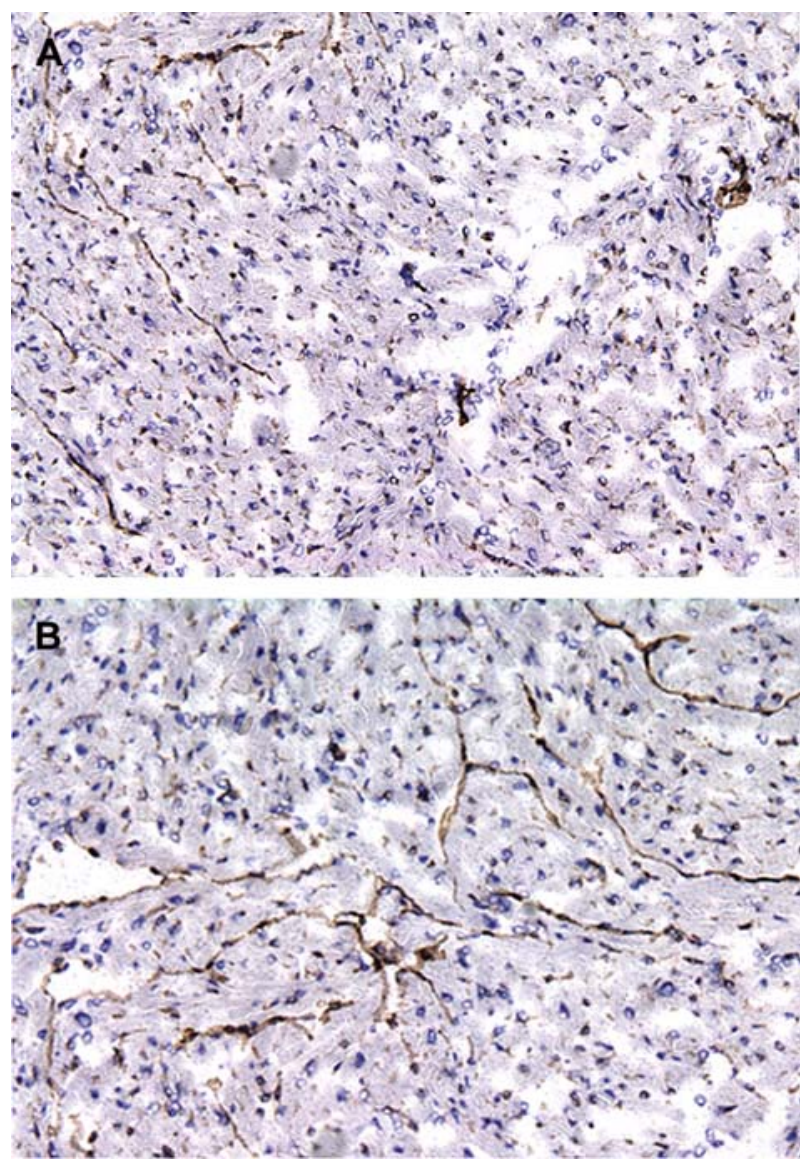

Figure 2. Immunohistochemical analyzes of $\mathrm{CD} 31^{+}$arterioles in the heart of (A) control mice and (B) G-CSF treated animals (magnification $\times 50$ ).

$r=0.85, P<0.001 ;$ strain in the posterior wall, $r=0.87, P<0.001)$. Blant-Altman analysis revealed that the difference obtained was within 2 SD of the mean difference for all strain values.

\section{Hemodynamic evaluation}

Hemodynamic data were acquired by conductance catheter on day 12, i.e. $48 \mathrm{~h}$ after the last dose of G-CSF or saline (Table II and Figure 5). Data were acquired both at baseline and after pre-load reduction. ESP, EDP and Tau were higher in G-CSFtreated mice $(P<0.05)$. Ees was lower after G-CSF therapy, but this difference did not reach statistical significance. The other hemodynamic parameters measured by this technique were not modified by G-CSF administration.

\section{Discussion}

The major findings of the study were that G-CSF induces the mobilization of HPC, EPC and CFU-F progenitors in $\mathrm{PB}$ according to very different patterns, and has a significant impact on the perfusion and function of the normal heart. Relatively little is
Het (\%)

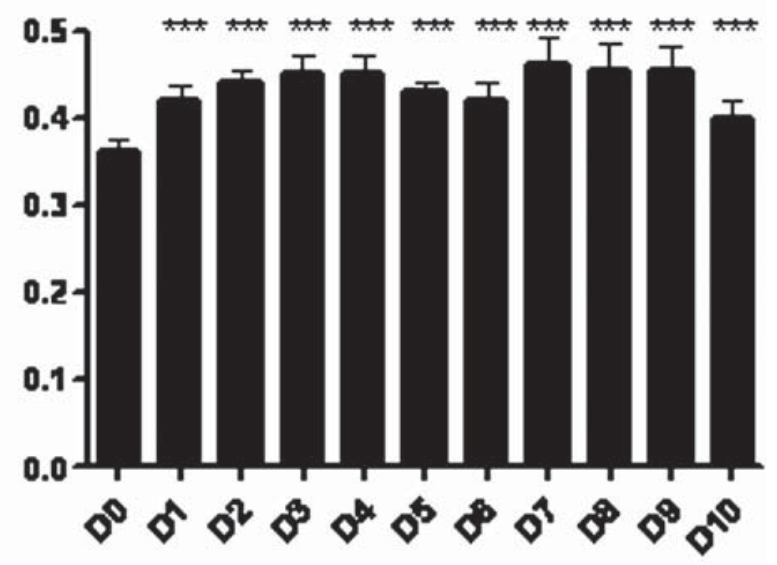

WBC $/ \mu I$ BM

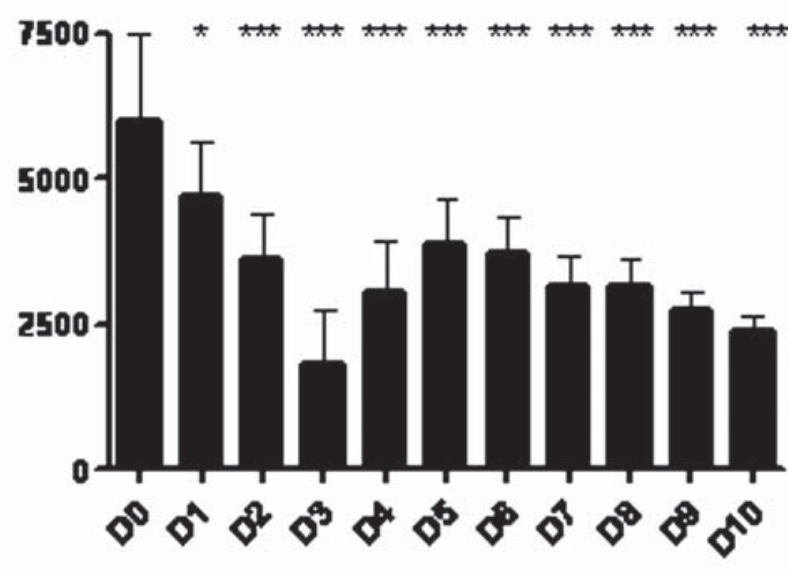

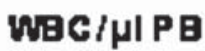

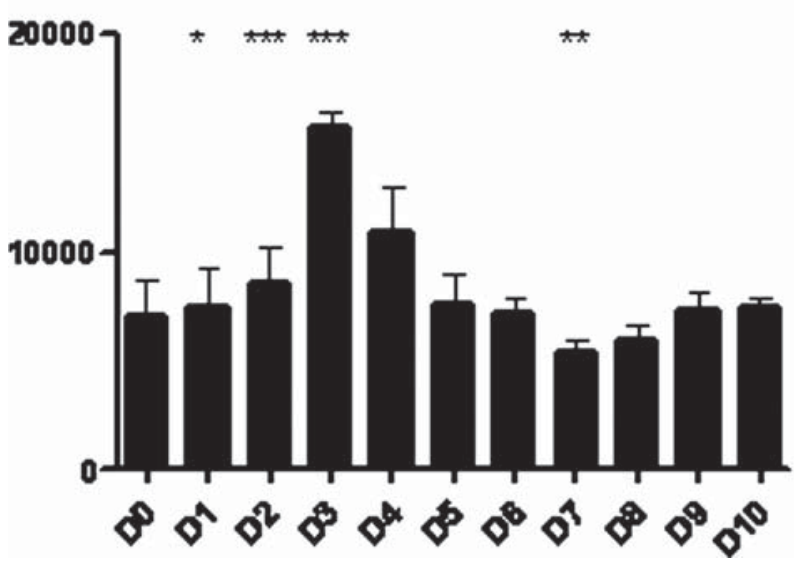

Figure 3. Hct and WBC count in BM and PB in mice before (day 0) and after 1-10 days of G-CSF therapy. $P$-values are given for comparisons with day 0 values: ${ }^{*} P<0.05,{ }^{* *} P<0.01,{ }^{* * *} P<0.001$.

known about the respective kinetics of HPC, EPC and CFU-F progenitor mobilization and the impact of $\mathrm{G}-\mathrm{CSF}$ administration on their pools in BM in normal mice. We used $50 \mu \mathrm{g} / \mathrm{kg}$ body weight of human G-CSF, a dose previously used for the mobilization of HSC in PB (21) that may nevertheless not be optimal. 
HPC

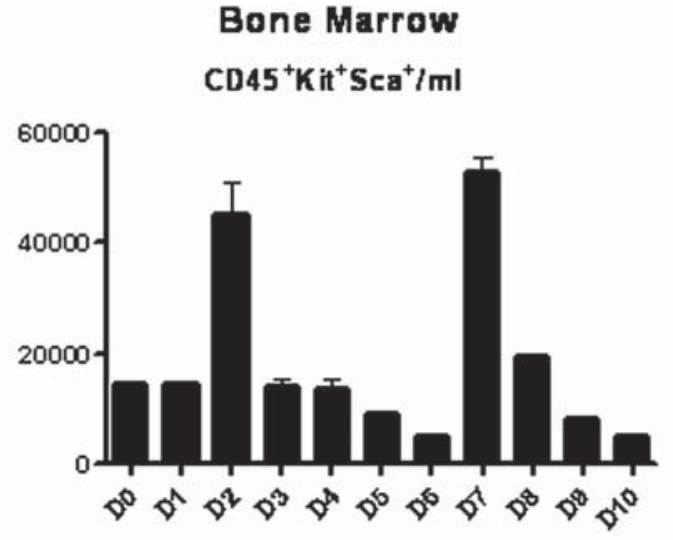

EPC

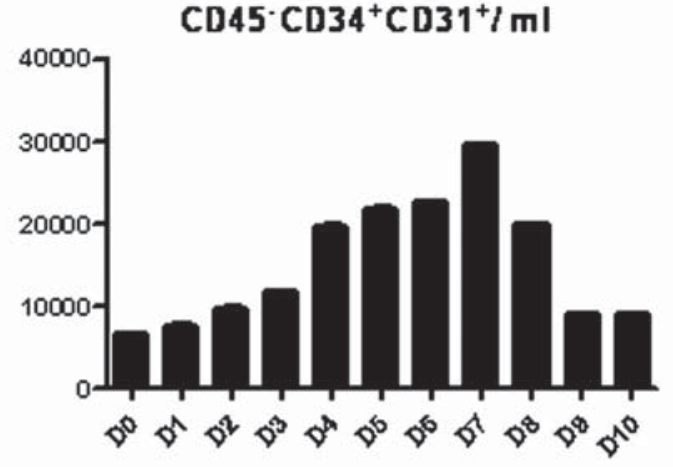

CFU-GM
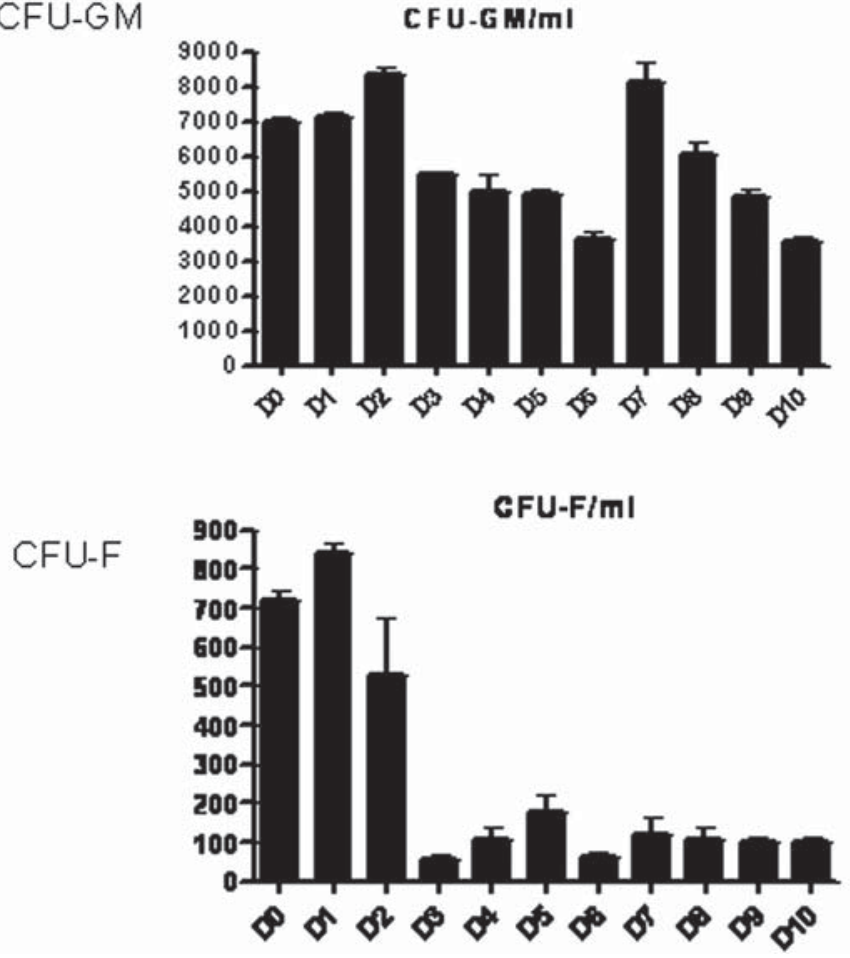

Peripheral Blood

$\mathrm{CD}{ }^{+} \mathrm{Kit}^{+} \mathrm{Sca}{ }^{+} / \mathrm{ml}$

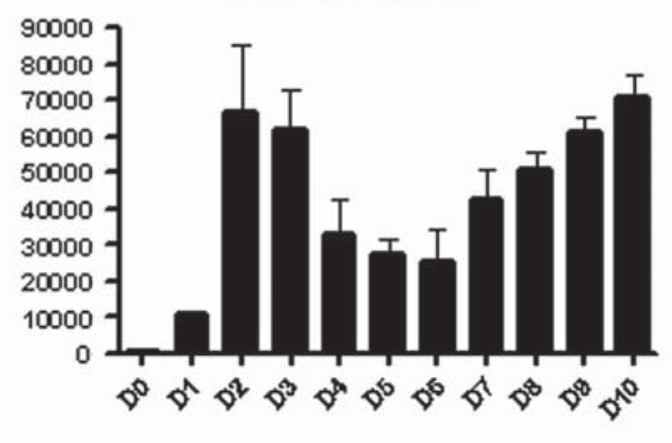

$\operatorname{cD45} \cdot \cos 4^{+} \operatorname{cDs}^{+}{ }^{+} / \mathrm{ml}$
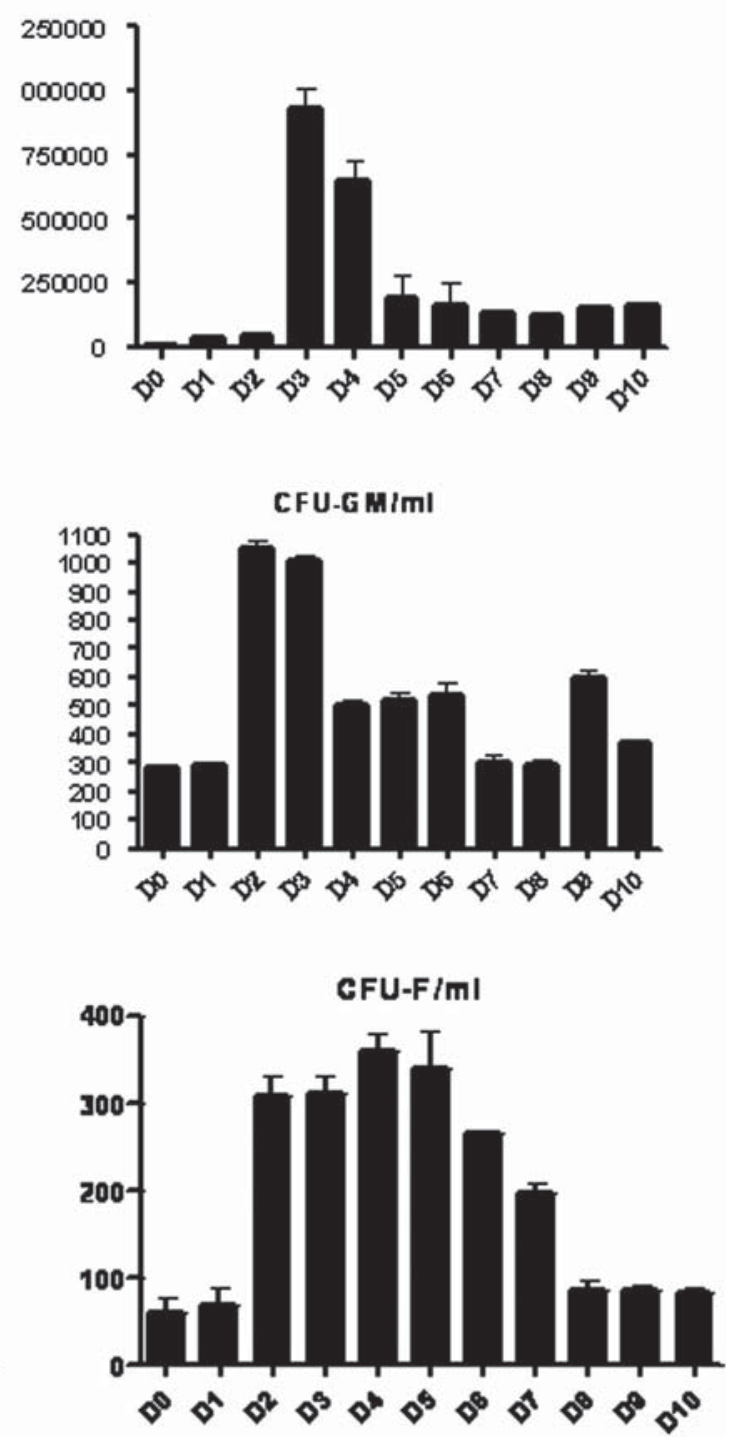

Figure 4. HPC and EPC, as well as CFU-GM and CFU-F, in PB of mice before (day 0) and after 1-10 days of G-CSF therapy.

The number of HPC in BM remained relatively stable throughout the study, except for two peaks occurring on days 2 and 7, followed each time by a major increase in PB. BM CFU-GM showed a similar pattern with the same, although less pronounced, two peaks, also followed by a significant elevation in the PB. A few previous studies have examined the effects of G-CSF on progenitor cells 
Table I. Echocardiographic parameters as evaluated on day 11, i.e. 24 hours after the last of 10 daily doses of G-CSF or saline $(n=12)$.

\begin{tabular}{lccc}
\hline & Saline & G-CSF & $P$-value \\
\hline HR (beats/min) & $236 \pm 92$ & $271 \pm 51$ & NS \\
LVIDd $(\mathrm{mm})$ & $3.8 \pm 0.4$ & $3.9 \pm 0.2$ & NS \\
LVIDs (mm) & $2.8 \pm 0.2$ & $2.8 \pm 0.4$ & NS \\
LVPWd (mm) & $0.9 \pm 0.1$ & $0.6 \pm 0.1$ & $P<0.001$ \\
IVSs $(\mathrm{mm})$ & $0.88 \pm 0.10$ & $0.86 \pm 0.10$ & $\mathrm{NS}$ \\
LVEF $(\%)$ & $66.1 \pm 3.2$ & $59.9 \pm 3.7$ & $P<0.05$ \\
CO $(\mu \mathrm{L} / \mathrm{s})$ & $217 \pm 71$ & $208 \pm 88$ & $\mathrm{NS}$ \\
Strain pw $(\%)$ & $34.5 \pm 6.8$ & $21.8 \pm 4.4$ & $P<0.01$ \\
Strain pw $(\%)$ & $29.8 \pm 8.5$ & $21.2 \pm 6.5$ & $P<0.05$ \\
\hline
\end{tabular}

LVIDd, left ventricular end-diastolic internal dimension; LVIDs, left ventricular end-systolic internal dimension; LVPWd, left ventricular posterior wall dimension in diastole; IVSs, interventricular septal dimension in systole; strain aw, strain in anterior wall; strain pw, strain in the posterior wall; NS, not significant.

simultaneously in $\mathrm{BM}$ and $\mathrm{PB}$, and animals were treated for a maximum of 6 consecutive days $(21,22)$. Chiang et al. (23) have assessed the impact of G-CSF on BM HSC in normal donors receiving 5 or $10 \mu \mathrm{g} / \mathrm{kg}$ G-CSF for 5 consecutive days. They showed that the numbers of nucleated cells and CD $34^{+}$cells/ $\mathrm{mL}$ showed a similar pattern of response in $\mathrm{BM}$ and $\mathrm{PB}$, with a peak around day 6. Recently, Lucas et al. (24) highlighted a circadian oscillation of HSC mobilization.

In our experiments, there was no strict correlation between the numbers of HPC, as identified by flow cytometric analysis, and the number of CFU-GM detected. This indicates that many HPC do not read out in colony assays. This could be explained by two mutually non-exclusive hypotheses. On the one hand, culture media used in clonogenic assays may not be suited for the growth of a fraction of the progenitors. On the other hand, G-CSF may interfere with the viability and clonogenic potential of a subpopulation of HPC. In particular, mobilized HPC are released from direct interactions with $\mathrm{BM}$ stromal cells, which may contribute to a decreased clonogenic potential.

The kinetics of CFU-F progenitors were different. Blood CFU-F stayed high to day 7 before returning to baseline levels, and marrow CFU-F showed a

Table II. Hemodynamic parameters as evaluated on day 12, i.e. $48 \mathrm{~h}$ after the last of 10 daily doses of G-CSF or saline $(n=12)$.

\begin{tabular}{lccc}
\hline & \multicolumn{1}{c}{ Saline } & G-CSF & $P$-value \\
\hline HR (beats/min) & $258 \pm 60$ & $282 \pm 74$ & NS \\
ESP $(\mathrm{mmHg})$ & $85.2 \pm 9.4$ & $97.2 \pm 11.0$ & $P<0.01$ \\
EDP $(\mathrm{mmHg})$ & $15.3 \pm 10.5$ & $31.6 \pm 5.2$ & $P<0.01$ \\
EDV $(\mu \mathrm{L})$ & $54.7 \pm 38.1$ & $68.9 \pm 24.0$ & $\mathrm{NS}$ \\
Stroke volume $(\mu \mathrm{L})$ & $28.1 \pm 10.5$ & $26.3 \pm 13.9$ & $\mathrm{NS}$ \\
Stroke work $(\mathrm{mmHg} /$ & $1636 \pm 764$ & $1589 \pm 643$ & $\mathrm{NS}$ \\
$\quad \mu \mathrm{L})$ & & & \\
Tau $(\mathrm{ms})$ & $13.2 \pm 2.8$ & $23.6 \pm 14.3$ & $P<0.05$ \\
Ees $(\mathrm{mmHg} / \mathrm{mL})$ & $2.22 \pm 1.23$ & $1.70 \pm 1.51$ & $\mathrm{NS}$ \\
\hline
\end{tabular}

profound reduction in their numbers. Flow cytometric analysis of cells within the CFU-F excluded a contamination by macrophages or endothelial cells.

EPC showed yet a different pattern of response to G-CSF administration. EPC numbers in BM increased gradually and were at their maximum on day 7, before waning partially. After a major increase in PB on days 3 and 4, EPC mobilization stabilized at much lower, albeit still highly significantly elevated, levels. These observations suggest that both rapid egress of pre-formed marrow EPC and a more gradual increase of the formation of EPC in the BM could account for intense EPC mobilization into the PB.

We thus demonstrated that the impact of G-CSF on the mobilization of HPC, EPC and CFU-F progenitors is time-dependant, involving both increased production in the $\mathrm{BM}$ and mobilization into the $\mathrm{PB}$, and displays very different kinetics for the various types of progenitor cells. Whereas HPC and CFU-F progenitors provide a relatively large window of opportunity for their collection from PB, EPC collection would be optimal on days 3-4.

G-CSF induces proliferation and activation of neutrophils and osteoclasts, which in turn secrete various proteases, including elastase, cathepsin $\mathrm{G}$, MMP-9 and MMP-2, which disrupt the SDF-1/ CXCR4 axis $(25,26)$. G-CSF thus leads to the release of cells characterized by their CXCR4 expression, including HPC, MPC and EPC $(27,28)$. Differences observed in the pattern of mobilization of HPC, EPC and CFU-F progenitors may therefore be the result of differences in adhesive molecule pattern at their surface. Pitchford et al. (29) described a differential mobilization of subsets of progenitor cells from the BM. Indeed, HPC mobilization is maximal when a CXCR4 antagonist is administrated to mice pretreated with G-CSF, while EPC mobilization is submaximal. In contrast, when mice are pretreated with VEGF, administration of a CXCR4 antagonist stimulates EPC mobilization and suppresses HPC mobilization.

Whereas it is well established for HPC, MPC and EPC mobilization in PB remains controversial. Discrepancies may be explained by variations in the source of cells obtained in different studies, differences in culture methods and lack of very specific and unequivocal markers and/or techniques to identify MPC and EPC. For example, diverse combinations of markers have been used to identify putative EPC independently from CD45 expression. However, it is now well established that the use of CD45 is recommended for the enumeration of EPC by flow cytometry $(30,31)$. Colony-forming unit endothelial cell (CFU-EC) assays have not yet been standardized in mice. Nevertheless, the accumulating evidence indicates that PB contains EPC. Their numbers were 

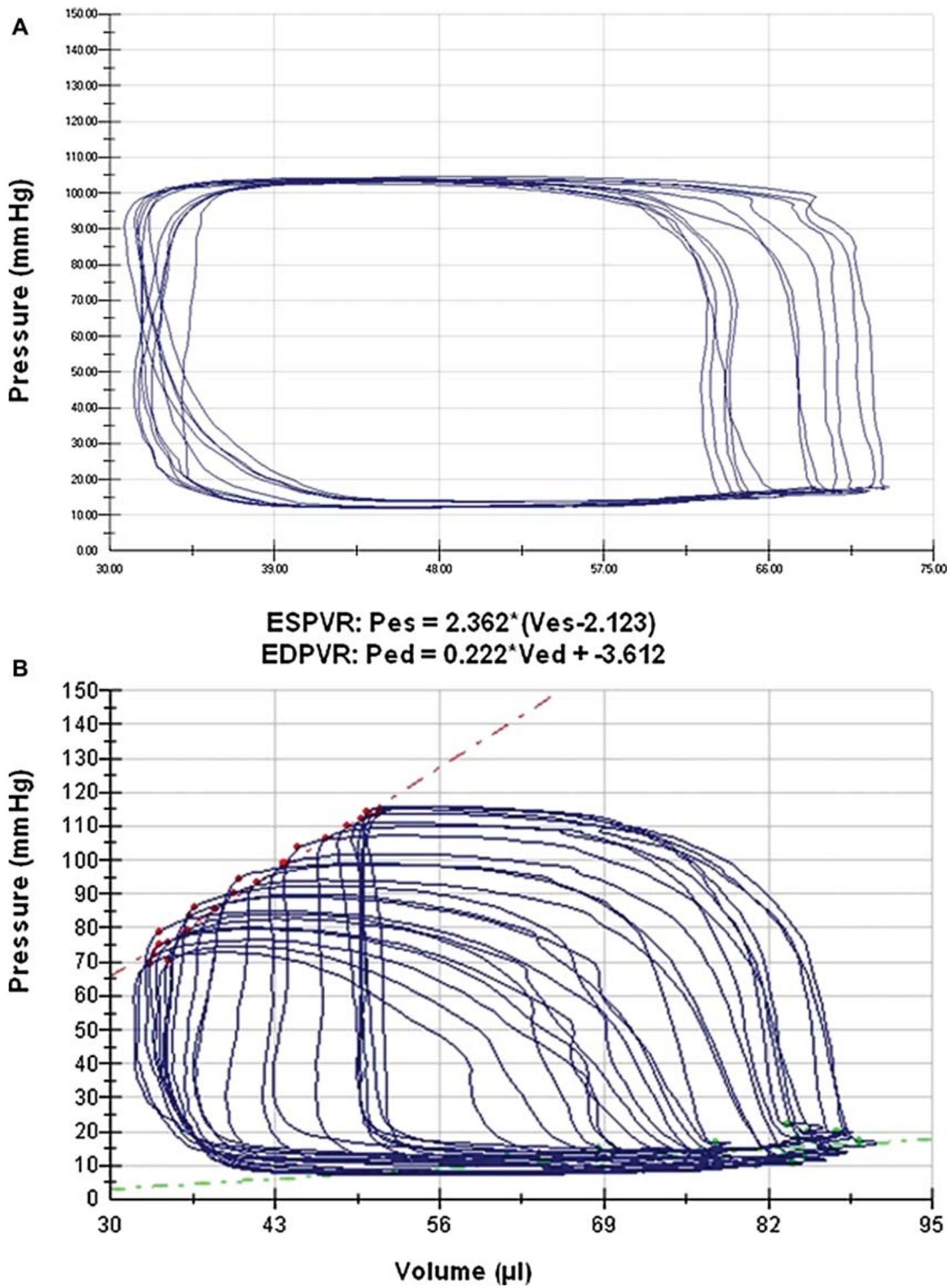

Figure 5. Representative PV loops in G-CSF treated mice (A) during baseline state and (B) after pre-load reduction obtained by gently compressing the inferior vena cava.

reduced in patients with cardiovascular disease (32) but they may be mobilized by growth factors such as G-CSF (33,34), GM-CSF (35) and erythropoietin (36). Similarly, several studies have reported detection of MPC in $\mathrm{PB}$, in particular in normal donors mobilized with G-CSF (37-40). Mansilla et al. (41) and Zvaifler et al. (42) found cells phenotypically identical to MSC circulating in normal subjects. Tatsumi et al. (38) did not detect MSC in murine PB under physiologic conditions but observed a strong mobilization of these cells after 9 days of treatment with G-CSF. In addition, Lund et al. (15) identified 
an increased number of CFU-F in the peripheral blood of volunteers mobilized by G-CSF.

Our study is the first to examine the impact of G-CSF therapy on the normal heart. We have demonstrated that short-term myocardial perfusion of normal mice is significantly enhanced by G-CSF therapy. By immunohistochemistry, we have also confirmed that the number of $\mathrm{CD}_{3} 1^{+}$arterioles increases. Whether this effect is produced by G-CSF acting directly in the heart or follows the homing of EPC newly formed in the BM and mobilized into the $\mathrm{PB}$ remains to be determined.

On the other hand, echocardiography and PV measurements demonstrated that G-CSF had an impact on LV systolic and diastolic function. By echocardiography, a decreased strain in the anterior and posterior walls indicated a reduced systolic deformation of the myocardium. There was no effect on global systolic function, as shown by the invasive hemodynamic approach, as the global contractility index, Ees, remained unchanged. However, data obtained from PV loops evidenced an impaired diastolic function. Tau, which measures the early active relaxation process, increased, indicating an abnormal LV relaxation. LV end-diastolic pressure also increased and, in the absence of any increase in LV end-diastolic volume, this suggests a lower myocardial compliance in G-CSF-treated mice. All these findings suggest that G-CSF exerts a rigidifying effect on the ventricular wall that may impair LV diastolic function. Higher doses could be tested in future experiments to determine whether superior concentrations of G-CSF would increase these phenomena. The mechanisms remain to be elucidated. Working hypotheses include a direct effect of G-CSF on the myocardium, homing to the heart of mobilized MPC, or a local inflammatory effect induced by excess neutrophils or other cells. Indeed, G-CSF could promote collagen synthesis $(43,44)$, MSC could differentiate into fibroblasts when localized in a pro-fibroblastic microenvironment $(45,46)$ and acute tissue injury has also been described in the lung after the use of G-CSF (47).

Our study has some limitations. HR was low despite anesthesia with ketamine at $50 \mathrm{mg} / \mathrm{kg}$ and xylasine at $2.5 \mathrm{mg} / \mathrm{kg}$, doses usually associated with high, stable HR, high fractional shortening and limited effects on LV inner dimension at the end of diastole (48). Other anesthesia protocols with pentobarbital $(30 \mathrm{mg} / \mathrm{kg})$ and isoflurane have had the same impact on HR. Nevertheless, the HR was quite reproducible in the two groups of experimental animals.

The results found of present study cannot be extrapolated directly to humans, even if there are similarities between species. For example, Kuznetsov et al. (49) reported the isolation of clonogenic, fibroblast-like cells with osteogenic and adipogenic potential from the blood of four mammalian species, including mice and humans. Although the phenotypic profile of stem cells is quite similar among species, the expression of markers can vary. Lucas et al. (24) also showed that HSC mobilization depends on a speciesspecific circadian rhythm that is inverted in humans compared with mice. Physiologic differences also exist, for example the HR is about $600 / \mathrm{min}$ in mice versus $80 / \mathrm{min}$ in humans, and murine metabolism is much more raised than that of humans. Furthermore, hemodynamic results obtained in mice may not be transposed to the response or data recorded in humans. No negative hemodynamic effects of G-CSF have been noted in patients or normal individuals during or after G-CSF administration (50) and recent reviews do not suggest negative hemodynamic consequences, such as impaired relaxation or reduced contractility, of G-CSF in adults following cardiac injury (51). However, differences between control and G-CSF-treated mice are probably not the consequence of reactive antibodies generated toward the human protein, because previous studies have shown that this phenomenon appears only after repeated cycles of G-CSF administration (52).

These new observations may have significance for the projected use of G-CSF in cardiovascular regenerative medicine. Further research should examine a number of important questions. Are the observed effects of G-CSF on the perfusion of the heart and rigidity of the ventricular wall reversible after cessation of G-CSF therapy? To what degree are these consequences of G-CSF use also encountered after myocardial infarction? Are these observations the result of direct effects of G-CSF on the myocardium, blood vessels or other cell types in the heart, or are they the result of homing of various progenitor cells mobilized into the PB from the BM? Are these results in mice relevant to humans? In the meantime, caution should be exerted and G-CSF use for cardiologic purposes should only be carried out in the setting of clinical trials with emphasis on safety together with efficacy endpoints.

\section{Acknowledgments}

This work was supported by grants from the National Fund for Scientific Research (FNRS, Belgium) and from the University of Liège. Marie Delgaudine is Télévie Research Assistant, Véronique Roelants Research Physician and Yves Beguin Research Director of FNRS.

Declaration of interest: The authors report no conflicts of interest. The authors alone are responsible for the content and writing of the paper. 


\section{References}

1. Cogle CR, Madlambayan GJ, Hubsher G, Beckman C, Speisman R, Tran-Son-Tay R, et al. Marrow cell therapies for cardiovascular diseases. Exp Hematol. 2008;36:687-94.

2. Pelacho B, Luttun A, Aranguren XL, Verfaillie CM, Prosper F. Therapeutic potential of adult progenitor cells in cardiovascular disease. Expert Opin Biol Ther. 2007;7:1153-65.

3. Ruvinov E, Dvir T, Leor J, Cohen S. Myocardial repair: from salvage to tissue reconstruction. Expert Rev Cardiovasc Ther. 2008;6:669-86.

4. Vassalli G, Vanderheyden M, Renders F, Eeckhout E, Bartunek J. Bone marrow stem cell therapy for cardiac repair: challenges and perspectives. Minerva Cardioangiol. 2007;55: 659-67.

5. Wollert KC. Cell therapy for acute myocardial infarction. Curr Opin Pharmacol. 2008;8:202-10.

6. Pelus LM. Peripheral blood stem cell mobilization: new regimens, new cells, where do we stand. Curr Opin Hematol. 2008; 15:285-92.

7. Schmitz N, Linch DC, Dreger P, Goldstone AH, Boogaerts MA, Ferrant A, et al. Randomised trial of filgrastim-mobilised peripheral blood progenitor cell transplantation versus autologous bone-marrow transplantation in lymphoma patients. Lancet. 1996;347:353-7.

8. Papayannopoulou T, Priestley GV, Nakamoto B, Zafiropoulos V, Scott LM. Molecular pathways in bone marrow homing: dominant role of alpha(4)beta(1) over beta(2)-integrins and selectins. Blood. 2001;98:2403-11.

9. Cottler-Fox MH, Lapidot T, Petit I, Kollet O, DiPersio JF, Link D, et al. Stem cell mobilization. Hematol Am Soc Hematol Educ Program. 2003;419-37.

10. Lapidot T, Petit I. Current understanding of stem cell mobilization: the roles of chemokines, proteolytic enzymes, adhesion molecules, cytokines, and stromal cells. Exp Hematol. 2002;30:973-81.

11. Kim S, von Recum H. Endothelial stem cells and precursors for tissue engineering: cell source, differentiation, selection, and application. Tissue Eng Part B Rev. 2008;14:133-47.

12. Levesque JP, Winkler IG, Larsen SR, Rasko JE. Mobilization of bone marrow-derived progenitors. Handb Exp Pharmacol. 2007;3-36.

13. Delorme B, Charbord P. Culture and characterization of human bone marrow mesenchymal stem cells. Methods Mol Med. 2007;140:67-81.

14. He Q, Wan C, Li G. Concise review: multipotent mesenchymal stromal cells in blood. Stem Cells. 2007;25:69-77.

15. Lund TC, Tolar J, Orchard PJ. Granulocyte colony-stimulating factor mobilized CFU-F can be found in the peripheral blood but have limited expansion potential. Haematologica. 2008;93:908-12.

16. Wang Y, Ripa RS, Jorgensen E, Hesse B, Mortensen S, Kastrup J. Mobilization of haematopoietic and non-haematopoietic cells by granulocyte-colony stimulating factor and vascular endothelial growth factor gene therapy in patients with stable severe coronary artery disease. Scand Cardiovasc J. 2007;41:397-404.

17. Abdel-Latif A, Bolli R, Zuba-Surma EK, Tleyjeh IM, Hornung CA, Dawn B. Granulocyte colony-stimulating factor therapy for cardiac repair after acute myocardial infarction: a systematic review and meta-analysis of randomized controlled trials. Am Heart J. 2008;156:216-26.

18. Ripa RS, Kastrup J. G-CSF therapy with mobilization of bone marrow stem cells for myocardial recovery after acute myocardial infarction: a relevant treatment? Exp Hematol. 2008; 36:681-6.

19. Walrand S, Jamar F, de Jong M, Pauwels S. Evaluation of novel whole-body high-resolution rodent SPECT (Linoview) based on direct acquisition of linogram projections. J Nucl Med. 2005;46:1872-80.

20. Roelants V, Delgaudine M, de Leval L, Beguin Y, Vanovershelde J, Jamar F, et al. Evaluation of the novel high-resolution rodent Linoview SPECT for myocardial perfusion imaging of mice. Eur J Nucl Med Mol Imaging. 2007;S244.

21. Bungart B, Loeffler M, Goris H, Dontje B, Diehl V, Nijhof W. Differential effects of recombinant human colony stimulating factor (rh G-CSF) on stem cells in marrow, spleen and peripheral blood in mice. Br J Haematol. 1990;76:174-9.

22. Varas F, Bernad A, Bueren JA. Granulocyte colony-stimulating factor mobilizes into peripheral blood the complete clonal repertoire of hematopoietic precursors residing in the bone marrow of mice. Blood. 1996;88:2495-501.

23. Chiang KY, Lamb L, Clark J, Worthington-White D, Rich I, Henslee-Downey PJ. Assessment of G-CSF stimulated BM hematopoietic stem cells in normal donors. Cytotherapy. 2002;4:55-63.

24. Lucas D, Battista M, Shi PA, Isola L, Frenette PS. Mobilized hematopoietic stem cell yield depends on species-specific circadian timing. Cell Stem Cell. 2008;3:364-6.

25. Fibbe WE, Hamilton MS, Laterveer LL, Kibbelaar RE, Falkenburg JH, Visser JW, et al. Sustained engraftment of mice transplanted with IL-1-primed blood-derived stem cells. J Immunol. 1992;148:417-21.

26. Levesque JP, Takamatsu Y, Nilsson SK, Haylock DN, Simmons PJ. Vascular cell adhesion molecule-1 (CD106) is cleaved by neutrophil proteases in the bone marrow following hematopoietic progenitor cell mobilization by granulocyte colony-stimulating factor. Blood. 2001;98:1289-97.

27. Heissig B, Hattori K, Dias S, Friedrich M, Ferris B, Hackett $\mathrm{NR}$, et al. Recruitment of stem and progenitor cells from the bone marrow niche requires MMP-9 mediated release of kitligand. Cell. 2002;109:625-37.

28. Yu X, Huang Y, Collin-Osdoby P, Osdoby P. Stromal cellderived factor-1 (SDF-1) recruits osteoclast precursors by inducing chemotaxis, matrix metalloproteinase-9 (MMP-9) activity, and collagen transmigration. J Bone Miner Res. 2003;18:1404-18.

29. Pitchford SC, Furze RC, Jones CP, Wengner AM, Rankin SM. Differential mobilization of subsets of progenitor cells from the bone marrow. Cell Stem Cell. 2009;4:62-72.

30. Case J, Mead LE, Bessler WK, Prater D, White HA, Saadatzadeh MR, et al. Human CD $34^{+} \mathrm{AC} 133^{+}$VEGFR-2 ${ }^{+}$cells are not endothelial progenitor cells but distinct, primitive hematopoietic progenitors. Exp Hematol. 2007;35:1109-18.

31. Timmermans F, Van Hauwermeiren F, De Smedt M, Raedt R, Plasschaert F, De Buyzere ML, et al. Endothelial outgrowth cells are not derived from $\mathrm{CD} 133^{+}$cells or $\mathrm{CD} 45^{+}$ hematopoietic precursors. Arterioscler Thromb Vasc Biol. 2007;27:1572-9.

32. Vasa M, Fichtlscherer S, Aicher A, Adler K, Urbich C, Martin $\mathrm{H}$, et al. Number and migratory activity of circulating endothelial progenitor cells inversely correlate with risk factors for coronary artery disease. Circ Res. 2001;89:E1-7.

33. Orlic D, Kajstura J, Chimenti S, Limana F, Jakoniuk I, Quaini $\mathrm{F}$, et al. Mobilized bone marrow cells repair the infarcted heart, improving function and survival. Proc Natl Acad Sci USA. 2001;98:10344-9.

34. Peichev M, Naiyer AJ, Pereira D, Zhu Z, Lane WJ, Williams M, et al. Expression of VEGFR-2 and AC133 by circulating human $\mathrm{CD} 34(+)$ cells identifies a population of functional endothelial precursors. Blood. 2000;95:952-8.

35. Cho HJ, Kim HS, Lee MM, Kim DH, Yang HJ, Hur J, et al. Mobilized endothelial progenitor cells by granulocytemacrophage colony-stimulating factor accelerate reendothelialization and reduce vascular inflammation after intravascular radiation. Circulation. 2003;108:2918-25. 
36. Bahlmann FH, De Groot K, Spandau JM, Landry AL, Hertel B, Duckert T, et al. Erythropoietin regulates endothelial progenitor cells. Blood. 2004;103:921-6.

37. Kassis I, Zangi L, Rivkin R, Levdansky L, Samuel S, Marx $\mathrm{G}$, et al. Isolation of mesenchymal stem cells from G-CSFmobilized human peripheral blood using fibrin microbeads. Bone Marrow Transplant. 2006;37:967-76.

38. Tatsumi K, Otani H, Sato D, Enoki C, Iwasaka T, Imamura $\mathrm{H}$, et al. Granulocyte-colony stimulating factor increases donor mesenchymal stem cells in bone marrow and their mobilization into peripheral circulation but does not repair dystrophic heart after bone marrow transplantation. Circ J. 2008;72:1351-8.

39. Cesselli D, Beltrami AP, Rigo S, Bergamin N, D'Aurizio F, Verardo R, et al. Multipotent progenitor cells are present in human peripheral blood. Circ Res. 2009;104:1225-34.

40. Liu ZJ, Zhuge Y, Velazquez OC. Trafficking and differentiation of mesenchymal stem cells. J Cell Biochem. 2009;106: 984-91.

41. Mansilla E, Marin GH, Drago H, Sturla F, Salas E, Gardiner C, et al. Bloodstream cells phenotypically identical to human mesenchymal bone marrow stem cells circulate in large amounts under the influence of acute large skin damage: new evidence for their use in regenerative medicine. Transplant Proc. 2006;38:967-9.

42. Zvaifler NJ, Marinova-Mutafchieva L, Adams G, Edwards CJ, Moss J, Burger JA, et al. Mesenchymal precursor cells in the blood of normal individuals. Arthritis Res. 2000;2:477-88.

43. Sesti C, Hale SL, Lutzko C, Kloner RA. Granulocyte colonystimulating factor and stem cell factor improve contractile reserve of the infarcted left ventricle independent of restoring muscle mass. J Am Coll Cardiol. 2005;46:1662-9.

44. SuganoY, Anzai T, Yoshikawa T, MaekawaY, Kohno T, Mahara $\mathrm{K}$, et al. Granulocyte colony-stimulating factor attenuates early ventricular expansion after experimental myocardial infarction. Cardiovasc Res. 2005;65:446-56.

45. Ai G, Su Y, Yan G, Wang M, Liu X, Xu H, et al. [The experimental study of bone marrow mesenchymal stem cells on the repair of skin wound combined with local radiation injury]. Zhonghua Yi Xue Za Zhi. 2002;82:1632-6.

46. Lee CH, Moioli EK, Mao JJ. Fibroblastic differentiation of human mesenchymal stem cells using connective tissue growth factor. Conf Proc IEEE Eng Med Biol Soc. 2006;1: 775-8.

47. Arimura $\mathrm{K}$, Inoue $\mathrm{H}$, Kukita $\mathrm{T}$, Matsushita $\mathrm{K}$, Akimot $\mathrm{M}$, Kawamata N, et al. Acute lung injury in a healthy donor during mobilization of peripheral blood stem cells using granulocyte-colony stimulating factor alone. Haematologica. 2005;90:ECR10.

48. Xu Q, Ming Z, Dart AM, Du XJ. Optimizing dosage of ketamine and xylazine in murine echocardiography. Clin Exp Pharmacol Physiol. 2007;34:499-507.

49. Kuznetsov SA, Mankani MH, Gronthos S, Satomura K, Bianco P, Robey PG. Circulating skeletal stem cells. J Cell Biol. 2001;153:1133-40.

50. Moog R. Mobilization and harvesting of peripheral blood stem cells. Curr Stem Cell Res Ther. 2006;1:189-201.

51. Kang S, Yang Y, Li CJ, Gao R. Effectiveness and tolerability of administration of granulocyte colony-stimulating factor on left ventricular function in patients with myocardial infarction: a meta-analysis of randomized controlled trials. Clin Ther. 2007;29:2406-18.

52. de Kruijf EJ, van Pel M, Hagoort H, Kruysdijk D, Molineux G, Willemze R, et al. Repeated hematopoietic stem and progenitor cell mobilization without depletion of the bone marrow stem and progenitor cell pool in mice after repeated administration of recombinant murine G-CSF. Hum Immunol. $2007 ; 68: 368-74$. 